\title{
Silybin and metabolic disorders
}

\author{
Pasquale Pignatelli ${ }^{1} \cdot$ Roberto Carnevale $^{2} \cdot$ Danilo Menichelli $^{1}$
}

Received: 3 October 2018 / Accepted: 9 October 2018 / Published online: 17 October 2018

(c) Società Italiana di Medicina Interna 2018

Mediterranean diet represents a fundamental strategy in the prevention of cardiovascular and metabolic disorders as demonstrated by observational and interventional trials [1]. Among the most represented elements of the Mediterranean diet are polyphenols that display protective effects on cardiometabolic disorders by counteracting oxidative stress that represent a key point of the preventive strategy in this setting. Hence, oxidative stress seems to be involved in both cardiovascular and metabolic disorders [2]. Indeed, atherosclerotic disease is associated with increased level of oxidative stress [3] as well as metabolic disorders such as non-alcoholic fatty liver disease (NAFLD) [4] and diabetes [5] (Fig. 1).

Amid the several natural elements proposed to be protective in these contexts is the flavolignan silybin [7]. The effect of silybin is reported on by Sciacqua and colleagues [6] in this issue of the Journal.

Silybin is the major active constituent of silymarin, and it represents about $50-70 \%$ of the silymarin extract. Similar to the other flavolignans, limiting factors for the use of silybin are its low solubility in water, low bioavailability, and poor intestinal absorption [7]. To counteract this aspect, different more soluble derivatives of silybin have been synthesized. In particular, when conjugated to vitamin $\mathrm{E}$ and phospholipids, silybin seems to significantly improve its bioavailability. Moreover, this combination also displays increased antioxidant and antifibrotic activity [7].

In liver cells, as well as in other types of cells, the common effects of silybin may be summarized as follows: (1) antioxidant; (2) direct or indirect (through the antioxidant

Pasquale Pignatelli

pasquale.pignatelli@uniroma1.it

1 Department of Internal Medicine and Medical Specialties, I Clinica Medica, Atherothrombosis Centre, Sapienza University of Rome, Viale del Policlinico 155, 00161 Rome, Italy

2 Department of Medical-Surgical Sciences and Biotechnologies, Sapienza University of Rome, Latina, Italy capability) modulator of inflammation and fibrogenesis; and (3) indirect or direct modulator of some intrahepatic metabolic pathways [7] (Fig. 1).

Silybin acts as an antioxidant because it inhibits radical formation, binds some radical species (scavenger), interferes with lipid peroxidation of membranes (and, therefore, modulates membrane permeability), and increases the intracellular content of scavengers [8]. Silybin inhibits the formation of oxidative species such as superoxide anion radicals and of nitric oxide, decreases the content of malondialdehyde, and totally abolishes the decrease of antioxidants such as glutathione, superoxide dismutase, catalase, glutathione peroxidase and glutathione reductase [7]. These results, which are dose dependent, have been documented in animal and human models of cardio-metabolic diseases [7].

Silybin also displays other metabolic effects; for instance, it interferes with some mechanisms of action of insulin. In fact, it modulates the uptake of glucose in adipocytes by blocking the insulin-dependent glucose transporter 4 . Several studies investigated this issue in human models. Thus, in a double-blind, randomized trial in patients with poorly controlled non-insulin-dependent diabetes mellitus and alcoholic liver disease [9], and in a randomized, double-blind, placebo-controlled trial in patients with type II diabetes [10], silybin significantly affects plasma levels of glucose and triglycerides, with a trend toward lower hemoglobin A1c levels.

The silybin-vitamin E-phospholipid complex was previously tested in different metabolic settings such as patients with NAFLD demonstrating its ability in reducing insulin resistance evaluated by the HOMA test after a 6-month treatment [11]. The effect of this complex on hypertensive patients with reduced glycemic control was investigated by Sciacqua and colleagues [6]. Hypertensive patients with normal glucose tolerance (NGT) but 1 -h post load plasma glucose $\geq 155 \mathrm{mg} / \mathrm{dl}$ ( 1 -h high), during the oral glucose tolerance test (OGTT), show higher insulin resistance and multiple target organ damage, and this represents an interesting model of metabolic disorder. The authors demonstrate that after 6 months of silybin 


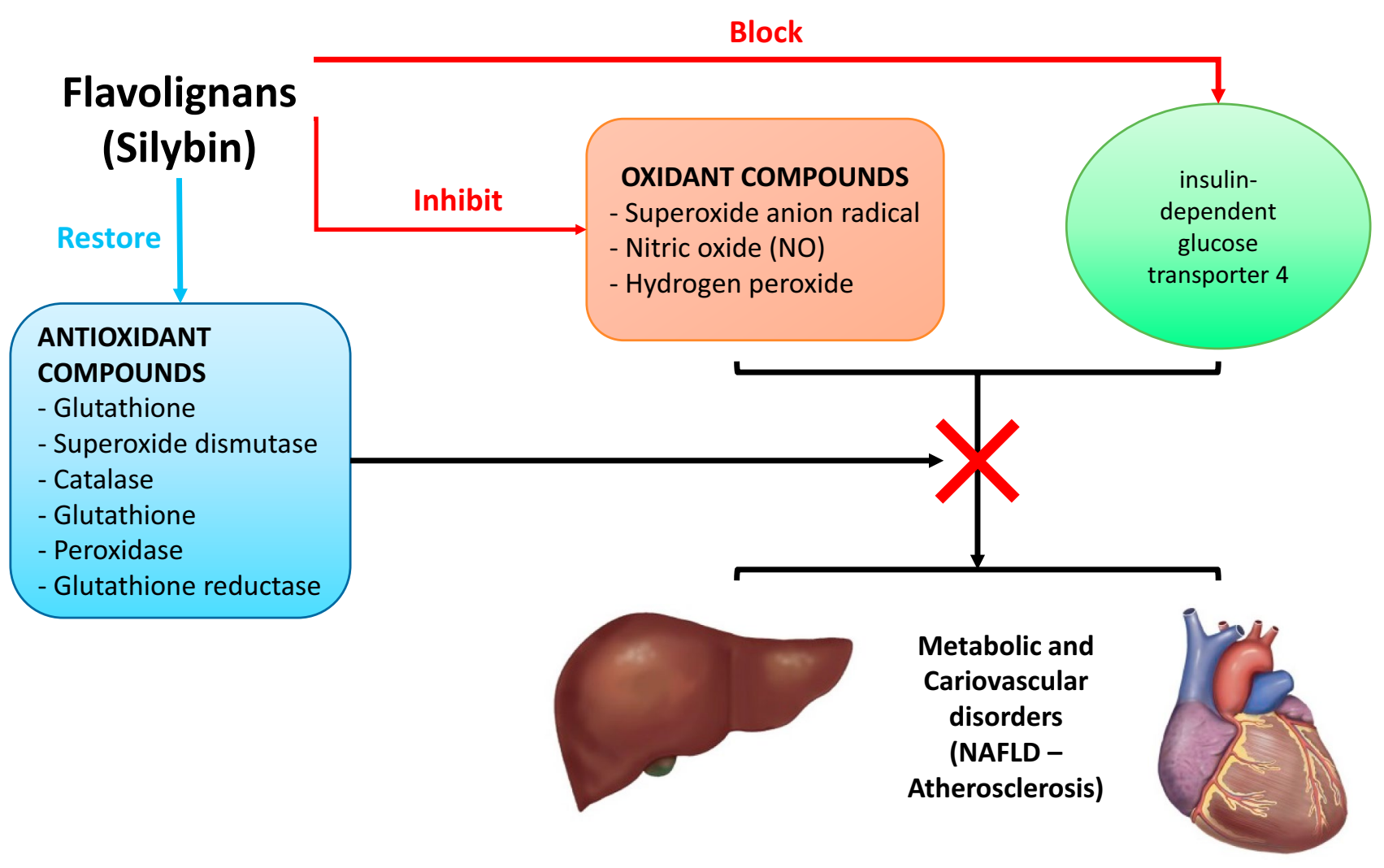

Fig. 1 Schematic representation of silybin on cardiometabolic diseases

intake, there is a significant improvement in metabolic profile. The glucose response during OGTT is significantly improved. Moreover, silybin intake is associated with a significant reduction of both clinical and central systolic blood pressure, with improvement in clinical and central pulse pressure, and reduction of arterial stiffness parameters. This is of particular interest because it was previously demonstrated that antihypertensive drugs are able to affect oxidative parameters [12], but the effect of polyphenols such as silybin in this setting has not been investigated until now. Similarly, other polyphenols were tested on arterial stiffness demonstrating their ability in modulating arterial relaxation, but the data on silybin are still poor. Hence, we are waiting for clinical randomized prospective trials to confirm the intriguing data here reported by Sciacqua and colleagues.

\section{Compliance with ethical standards}

Conflict of interest The authors declare that they have no conflict of interest.

Statement on human and animal rights This article does not contain any studies with human participants or animals performed by any of the authors.
Informed consent None.

\section{References}

1. Violi F, Pignatelli P, Basili S (2010) Nutrition, supplements, and vitamins in platelet function and bleeding. Circulation 121(8):1033-1044. https://doi.org/10.1161/CIRCULATIO NAHA.109.880211

2. Violi F, Pignatelli P (2012) Platelet oxidative stress and thrombosis. Thromb Res 129(3):378-381. https://doi.org/10.1016/j.throm res.2011.12.002

3. Violi F, Pignatelli P, Pignata C, Plebani A, Rossi P, Sanguigni V, Carnevale R, Soresina A, Finocchi A, Cirillo E, Catasca E, Angelico F, Loffredo L (2013) Reduced atherosclerotic burden in subjects with genetically determined low oxidative stress. Arterioscler Thromb Vasc Biol 33(2):406-412. https://doi.org/10.1161/ ATVBAHA.112.300438

4. Polimeni L, Del Ben M, Baratta F, Perri L, Albanese F, Pastori D, Violi F, Angelico F (2015) Oxidative stress: new insights on the association of non-alcoholic fatty liver disease and atherosclerosis. World J Hepatol 7(10):1325-1336. https://doi.org/10.4254/ wjh.v7.i10.1325

5. Santilli F, Lapenna D, La Barba S, Davi G (2015) Oxidative stress-related mechanisms affecting response to aspirin in diabetes mellitus. Free Radical Biol Med 80:101-110. https://doi. org/10.1016/j.freeradbiomed.2014.12.010

6. Sciacqua A, Perticone M, Tripepi G, Addesi D, Cassano V, Maio R, Sesti G, Perticone F (2018) Metabolic and vascular effects 
of silybin in hypertensive patients with high one-hour post-load plasma glucose. Intern Emerg Med. https://doi.org/10.1007/s1173 9-018-1951-6

7. Loguercio C, Festi D (2011) Silybin and the liver: from basic research to clinical practice. World J Gastroenterol 17(18):22882301. https://doi.org/10.3748/wjg.v17.i18.2288

8. Trouillas P, Marsal P, Svobodova A, Vostalova J, Gazak R, Hrbac J, Sedmera P, Kren V, Lazzaroni R, Duroux JL, Walterova D (2008) Mechanism of the antioxidant action of silybin and 2,3-dehydrosilybin flavonolignans: a joint experimental and theoretical study. J Phys Chem A 112(5):1054-1063. https://doi. org/10.1021/jp075814h

9. Lirussi F, Beccarello A, Zanette G, De Monte A, Donadon V, Velussi M, Crepaldi G (2002) Silybin-beta-cyclodextrin in the treatment of patients with diabetes mellitus and alcoholic liver disease. Efficacy study of a new preparation of an anti-oxidant agent. Diabetes Nutr Metab 15(4):222-231
10. Huseini HF, Larijani B, Heshmat R, Fakhrzadeh H, Radjabipour B, Toliat T, Raza M (2006) The efficacy of Silybum marianum (L.) Gaertn. (silymarin) in the treatment of type II diabetes: a randomized, double-blind, placebo-controlled, clinical trial. Phytother Res 20(12):1036-1039. https://doi.org/10.1002/ptr.1988

11. Federico A, Trappoliere M, Tuccillo C, de Sio I, Di Leva A, Del Vecchio Blanco C, Loguercio C (2006) A new silybin-vitamin E-phospholipid complex improves insulin resistance and liver damage in patients with non-alcoholic fatty liver disease: preliminary observations. Gut 55(6):901-902. https://doi.org/10.1136/ gut.2006.091967

12. Germano G, Sanguigni V, Pignatelli P, Caccese D, Lenti L, Ragazzo M, Lauro R, Violi F (2004) Enhanced platelet release of superoxide anion in systemic hypertension: role of AT1 receptors. J Hypertens 22(6):1151-1156 